\title{
Socio-Cultural Factors Influencing Uptake of Skilled Childbirth Services among Women in Kaiti Division, Makueni District (Kenya)
}

\author{
Anthony Wambua Mathulu' ${ }^{1}$, Benard Wambua Mbithi ${ }^{\mathbf{2}}$ \\ ${ }^{1}$ Department of Health, Government of Makueni County, Kenya \\ ${ }^{2}$ Jomo Kenyatta University of Agriculture and Technology, Kenya
}

\section{Article Info \\ Article history: \\ Received Mar 12, 2017 \\ Revised May 15, 2017 \\ Accepted May 29, 2017}

\section{Keywords:}

Skilled Birth Attendants

Skilled Childbirth Services

Socio-Cultural

Women of Reproductive Age

\begin{abstract}
Each year, over 500,000 women die from the complications of pregnancy and child birth, almost all of them in the developing countries. This trend can be addressed by increasing the rates of skilled care during childbirth. This study therefore sought to establish the socio-cultural factors influencing uptake of skilled childbirth care which has remained low in Kaiti Division. The researchers applied a descriptive cross-sectional study design which involved women of childbearing age (15-49 years). The study was conducted in March 2010 and had a sample size of 246 women which was randomly selected from the estimated target population of 12,077. The researchers applied both quantitative and qualitative approaches. The tests of significance employed included Fisher's exact test, chi-square, test and logistic regression. The study established that the proportion of women attended to by the skilled attendant within various age cohorts was higher (58.9\%) amongst the youth/adolescent (15-24 years) $(\mathrm{P}$-value $=0.091>$ $0.05, \chi^{2} 10.915$ df 6).). Skilled attendance declined among the grandmultiparas (para4 and above) from 7.7\% in Para 4-5 to $2 \%$ in Para 6+ (Pvalue $=.000<0.05, \chi^{2} 34.888$ df 3 ; Para $1(\mathrm{p}=0.000$, OR 28.391), Para $2-3$ (p $=0.000$, OR 7.564), Para 4-5( $\mathrm{p}=0.030$, OR 3.493) Further findings indicated that the principal decision maker $(46.7 \%)$ on type of assistant in the last delivery was the woman (P-value $=0.000<0.05, \chi^{2} 56.076$ df 5 ). However, the husband was the leading (39.5\%) decision maker in use of a skilled assistant in the last delivery ( $\mathrm{p}=0.000$, OR 15.667). More than two thirds $(70.7 \%)$ of the respondents who performed a ceremony prayed for safe delivery in their last delivery. The study concluded that women's parity, decision making and religion were significant in use of skilled childbirth services.
\end{abstract}

Copyright (C) 2017 Institute of Advanced Engineering and Science. All rights reserved.

Corresponding Author:

Anthony Wambua Mathulu, Department of Health, Government of Makueni County, Kenya,

P.O. Box 19-90137, Kibwezi (Kenya).

E-mail:mathulu@yahoo.com;amathulu@gmail.com

\section{INTRODUCTION}

Each year, over 500,000 women die from the complications of pregnancy and childbirth, almost all of them in the developing countries [1],[2]. More than $70 \%$ of the maternal deaths are attributed to five major complications (severe bleeding, infections, unsafe abortions, eclampsia, and obstructed labour) and $77 \%$ occur during or shortly after childbirth arguing the need for skilled health care during this period [3]-[5]. Increasing the rates of skilled care during childbirth is widely recognized as a priority strategy for reducing maternal mortality and as the target indicator to measure progress towards the Global Goal of improving maternal Health [1],[6],[7]. Worldwide, $63.1 \%$ of births are attended to by a skilled health care worker. 
Although skilled health care personnel in the developed countries attend to virtually all births, the corresponding figure is $59.1 \%$ in developing countries and only $34.3 \%$ in the least developed countries. In Africa and Asia, only $46.5 \%$ and $60.8 \%$ respectively, of women give birth with the help of a skilled attendant. In the least developed regions, the lowest proportions of births attended by a skilled attendant can be traced in Eastern Africa (34.2\%) [8]. Ethiopia is considered to have the lowest skilled attendance (8\%) in the world [9]. In Kenya, skilled birth attendance has not reached the expected universal coverage despite various strategies such as the free maternity services and the Beyond Zero Campaign and the output Based Approach [4]. Only 2 in 5 births were delivered by a health professional between 2003 and 2009 [10],[11]. Currently skilled birth attendance in Kenya stands at 62\% [12]. In Makueni County, universal coverage for skilled childbirth has not been attained either and deliveries remained between $7 \%$ and $50 \%$ with maternal deaths being reported in some areas. Kaiti Division managed about $42 \%$ of deliveries under skilled health care. The situation is compounded by the fact that there are women living near the health facilities who go there for antenatal care but decline to go there for assistance during delivery choosing to deliver in risky environments at home under the care of unskilled attendants [13],[14]. This study therefore sought to determine the socio-cultural factors influencing uptake of skilled childbirth services among women of reproductive age.

\section{RESEARCH METHOD}

This was a descriptive cross-sectional study involving women of childbearing age $(12,077)$ in Kaiti Division who had delivered at least once. Both quantitative and qualitative approaches were applied. A sample size of 246 women was selected from the estimated target population of 12,077 women of childbearing age (15-49 years) in Kaiti Division.

The study was carried out in Kaiti Division, which is in Makueni District, Eastern Province of Kenya. It has a total surface area of $184 \mathrm{~km}^{2}$ and a population of 50,323, four Locations, seventy-eight villages and 9,033 households [15].

Probability sampling was applied in selection of 246 subjects (women 15-49 years). In order to obtain a representative sample from the target population for the interviews, a multistage sampling technique was applied. A lottery method was applied to ensure that each individual unit was picked up from the whole group. The first stage involved random selection of two locations from the four locations in the division. The two locations (Kivani and Ukia) have a total of six sub-locations. In the second stage, twelve villages were randomly selected from the six sub locations, which have forty-three villages. In the next stage, 246 households within the twelve villages were randomly selected. This was facilitated by a household list prepared by the village elders. Within the 246 households, women of reproductive age who had delivered at least once were selected randomly. For diverse opinions only one woman was randomly selected per a household.

The process of allocating units of study in the twelve villages was based on the probability proportion of the sample size. This was applied because the villages did not have the same number of women of reproductive age. The formula used was:

$$
\mathrm{n}_{1}=\frac{\mathrm{N}_{1} \times \mathrm{Xn}}{\mathrm{N}_{\mathrm{T}}}
$$

Where $\mathrm{n}=$ the total sample size of study (246 women)

$$
\mathrm{n}_{1}=\text { village sample size }
$$

$\mathrm{N}_{1}=$ village subpopulation size

$\mathrm{N}_{\mathrm{T}}=$ total number of study population in villages.

A criterion for inclusion was any childbearing women who had delivered at least once and who were between 18-49 years. The exclusion criterion was women who had never delivered. Discussants for Focus Group Discussions were those who had delivered at least once (18-49 years) but with homogenous characteristics such as same age bracket, education, social and economic status.

The sample size of 246 respondents was determined using the formula by Fisher [16]. Where the entire population is 10,000 or more. The study population is 12,077 .

$$
\text { Formula } n=\frac{z^{2} p q}{d^{2}}
$$


Where: $\mathrm{n}=$ desired sample size (where population is greater than 10,000 ), $\mathrm{Z}=$ the standard normal deviate set at 1.96 which corresponds to the $95 \%$ confidence level, $\mathrm{P}=$ the proportion in the target population estimates to have a particular characteristic (Skilled birth attendance in Makueni 20\%-Makueni Health Management Information System [13], $\mathrm{q}=1.0-\mathrm{p}, \mathrm{d}=$ degree of accuracy desired, set at .05 .

A pre-tested questionnaire was employed to obtain information on demography and health facility related issues among women and health workers. Six research assistants who had completed form four and who are fluent in the local language administered the questionnaire to women. Focus Group Discussion was used as a qualitative method to explore health facility related issues, experiences and opinions on skilled birth and other childbirth related issues, amongst the women who had delivered at least once. Five discussions were facilitated using a designed guide, which focused on themes and sub-themes. Each had eight people from various villages in Kaiti Division and was moderated by the researcher. A three-day training supplemented by practical exercises was given to the six research assistants and two supervisors.

Data editing and cleaning was done to ensure that the data were accurate, consistent with the other facts gathered, uniformly entered, as complete as possible and had been well arranged to facilitate coding and tabulation. Once the respondents filled the questionnaire, the data was coded and entered into the computer. Codes for the open-ended questions were developed based on the pre-test results and on the responses from the first survey sites.

Data analysis was through statistical package for social scientists (SPSS). Frequency tables and charts were used in presentation of findings. Cross-tabulation was used to compare variables. The associations between various factors and outcomes of interest were explored both separately for each variable (univariate) and combining the variables (bivariate). Tests of significance were through use of Chi-square, Fisher's exact test and logistic regression "enter model". Logistic regression was used for the factors with a P-value less than 0.05 in univariate analysis. A p-value less than 0.05 were deemed statistically significant.

Focus Group Discussion thematic coding and data editing was done to ensure that the data were accurate, as complete as possible and had been well arranged to aid in smooth analysis. Qualitative data analysis was through descriptive outlines by grouping findings into themes and sub-themes, which were guided by the study objectives. These on site summaries were enhanced using filed notes taken by an assistant or observer during the Focus Group Discussions.

Participation of respondents in the research was voluntary. An informed consent was obtained from the respondents. Selection and training of interviewers was strict. Only those who had completed form four and who could speak the local language (Kikamba) were selected by the local provincial administrators in liaison with the village elders. The interviewers were individuals from the area who could be trusted to hold sensitive and confidential information. They were preferably people of pleasant disposition, well mannered, well dressed and reliable. Cultural sensitivity and confidentiality were maintained in the study. Permission for entry into the area was sought from District Medical Officer of Health and the provincial administration while the Ministry of Higher Education and the Great Lakes University of Kisumu Research Committee granted approval for the research.

\section{RESULTS AND ANALYSIS}

\subsection{Results}

\subsubsection{Age}

The mean age of the interviewed women was 32.3 years while at first delivery it was 21.4 years. The descriptive statistics for these variables are summarized in Table 1.

Table 1. Descriptive Statistics for Age of Respondents at 1st Delivery $(n=246)$

\begin{tabular}{cccccccc}
\hline Age & $\mathrm{n}$ & Mean & Median & Mode & SD & Minimum & Maximum \\
\hline Age of respondents & 246 & 32.3 & 31.4 & 40 & 8.3 & 18 & 11 \\
Age at marriage & 206 & 20.2 & 19.9 & 20 & 3.2 & 30 \\
Age at $1^{\text {st }}$ delivery & 246 & 21.4 & 20.8 & 20 & 3.2 & 12 & 35 \\
\hline
\end{tabular}

Source: Research data 2010

Figure 1 summarizes age distribution of respondents by attendance in the last delivery. The study findings in Figure 1 established that the proportion of women attended to by skilled attendant within various age cohorts was higher (58.9\%) amongst the youth/adolescent (15-24 years) than amongst the adults (25-49 
years) $(45.2 \%)$. The chi-square test performed did not indicate a significant relationship between age and type of assistant in the last delivery (P-value $\left.=0.091>0.05, \chi^{2} 10.915 \mathrm{df} 6\right)$.

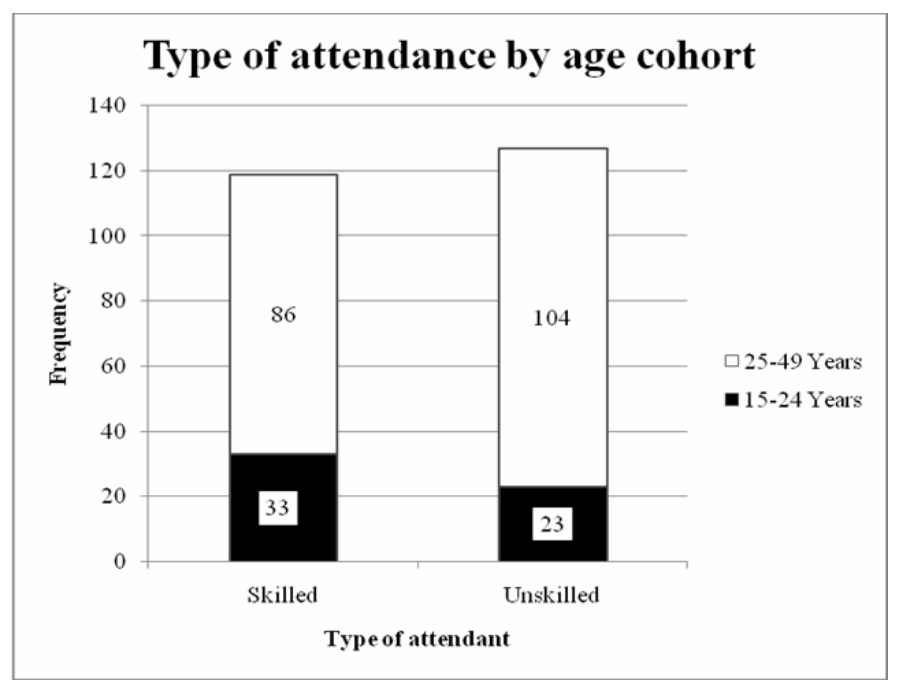

Source: Research data 2010

Figure 1. Type of Attendance by Age Cohort in Last Delivery $(n=246)$

\subsubsection{Parity}

Skilled attendance declined among the grand-multi paras (Para 4 and above) from $7.7 \%$ in Para 4-5 to $2 \%$ in Para 6+ as indicated in Table 2. According to the FGD discussants, multiparas have experienced previous uneventful deliveries and hence they don't anticipate any complications in subsequent deliveries "kusyaa nesa twana twambee tunenganae wikwatyo kana vayithwa mathina syana ila siatiiye". Statistical tests pointed to a significant relationship between parity and skilled attendance $\left(\mathrm{P}\right.$-value $=.000<0.05, \chi^{2}$ $34.888 \mathrm{df} 3)$. Logistic regression indicated that the likelihood of skilled assistance decreased with parity (Para $1(\mathrm{p}=0.000$, OR 28.391), Para 2-3 ( $\mathrm{p}=0.000$, OR 7.564), Para 4-5( $\mathrm{p}=0.030$, OR 3.493).

Table 2. Skilled Attendance by Parity $(n=246)$

\begin{tabular}{cccccc}
\hline \multirow{2}{*}{ Type of attendant } & \multicolumn{5}{c}{ Parity. } \\
& Para 1 & Para 2-3 & Para 4-5 & Para 6+ & Total \\
\hline Skilled attendant & $36(14.6)$ & $59(24)$ & $19(7.7)$ & $5(2)$ & $119(48.4)$ \\
Unskilled attendant & $10(4.1)$ & $55(22.3)$ & $34(13.8)$ & $28(11.4)$ & $127(51.6)$ \\
Total & $46(18.7)$ & $114(46.3)$ & $53(21.5)$ & $33(13.4)$ & $246(100)$ \\
\hline
\end{tabular}

Source: Research data 2010

\subsubsection{Marital status}

Figure 2 below depict skilled attendance by marital status of respondents in their last delivery. The study data in Figure 2 indicated that most (72\%) of those attended to by skilled birth attendants in their last delivery were in the married monogamy relationship. None of the widows were attended to by skilled attendants. This is probably due to lack of male support. There was no significant relationship between marital status and use of skilled childbirth services in last delivery (P-value $=.396>0.05, \chi^{2} 5.170 \mathrm{df} 5$ ). 


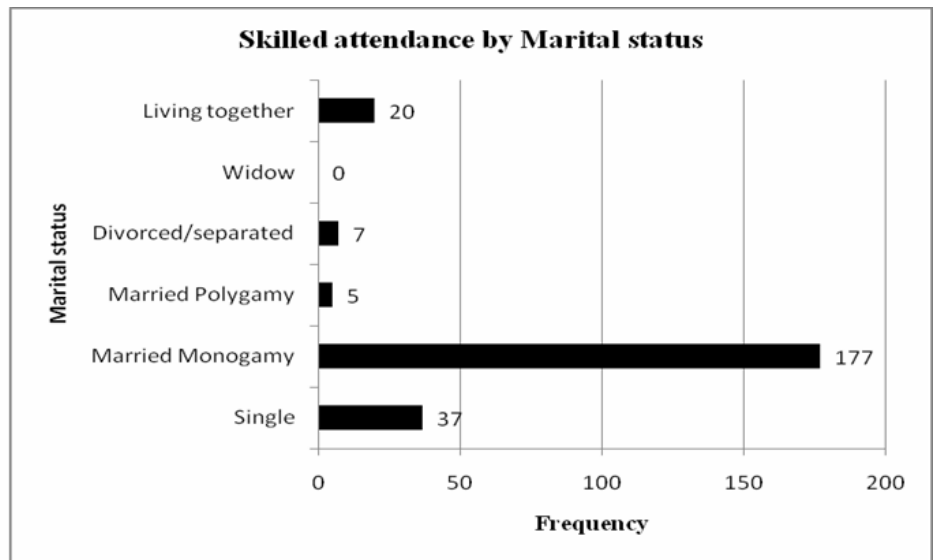

Source: Research data 2010

Figure 2. Skilled Attendance by Marital Status of Respondents ( $\mathrm{n}=119)$

\subsubsection{Religion}

Figure 3 below is a summary of type of assistance in the last delivery by Religious affiliation of the respondents. The study findings in Figure 3 demonstrates that more than half $(53.8 \%)$ of the women attended to by skilled attendants were Catholics. None of those without any religious affiliation were assisted by skilled attendants in their last delivery. The Statistical test performed depicted a significant relationship between religion and type of assistant in last delivery (P-value $=0.040<0.05, \square^{2} 8.327$ df 3 ). Further test with logistic regression indicated that those in indigenous religious affiliations and those without any affiliation were less likely to seek assistance from a skilled attendant ( $\mathrm{p}=0.029$, OR 0.174).

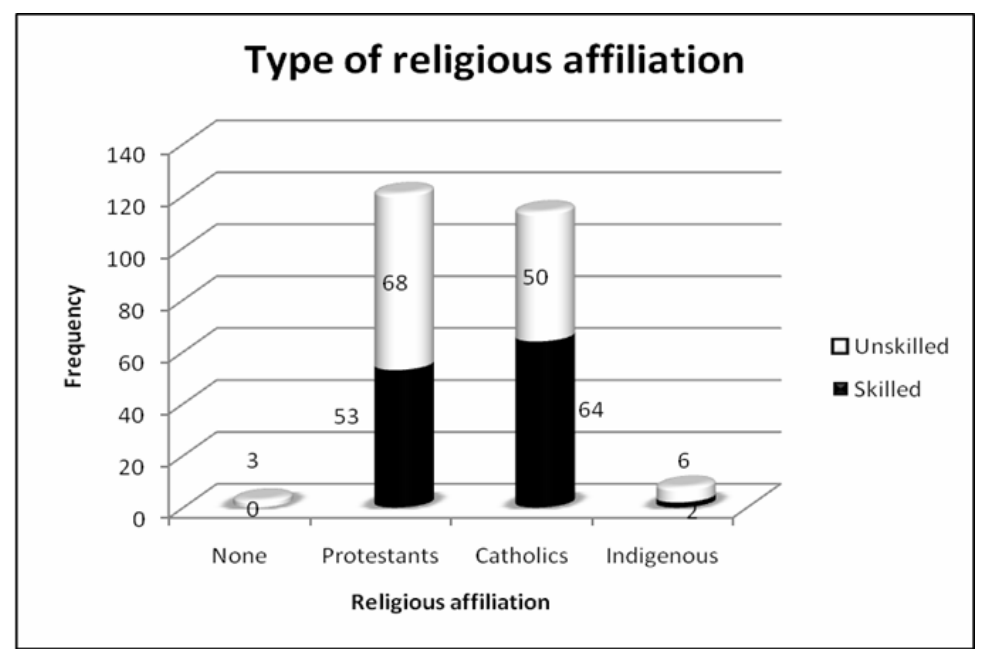

Source: Research data 2010

Figure 3. Type of Assistance by Religious Affiliation ( $\mathrm{n}=246)$

\subsubsection{Decision-making}

Figure 4 below indicates decision makers regarding the type of assistant in the last delivery. The study findings in Figure 4 show that the principal $(46.7 \%)$ decision maker on type of assistant in last delivery was the woman. However, the husband was the leading $(39.5 \%)$ decision maker in use of a skilled assistant in the last delivery. In the Focus Group Discussions, the discussants unanimously agreed that a woman is the key decision maker regarding the place of delivery and type of attendant in delivery "mwene kyathi niwe uamuaa kaingi". The translation is "The concerned person makes decision most times". Chi-square test indicated a significant relationship between decision-making and type of assistance in last delivery $(\mathrm{P}$-value $=$ 
$0.000 \square 0.05, \square^{2} 56.076 \mathrm{df} 5$ ). Logistic regression depicts that the skilled attendants ( $=0.000$, OR 120) and male partners' decisions ( $\mathrm{p}=0.000$, OR 15.667) were more likely to result to skilled attendance than the women's decision ( $\mathrm{p}=0.000$, OR 3.718). The other influentials decisions were not significant.

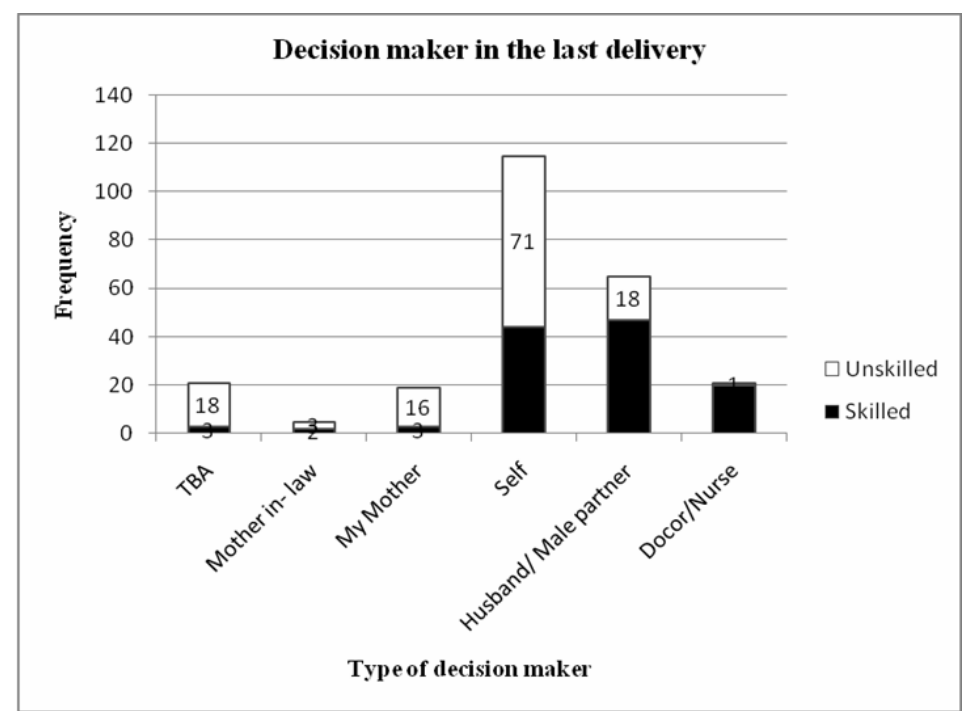

Source: Research data 2010

Figure 4. Decision Regarding Delivery Assistant ( $n=246)$

\subsubsection{Cultural taboos}

The study data in Table 3 depicts that more than two thirds $(70.7 \%)$ of the respondents who performed a ceremony prayed for safe delivery in their last pregnancy while $1.6 \%$ underwent cleansing. The FGD participants disclosed that "spitting on palms" and prayers are used as common methods of healing of mothers in prolonged labour. There was no significant relationship between the ceremonies performed and use of skilled childbirth services in the last pregnancy/delivery ( $\mathrm{p}$-value $>0.05$ ).

Table 3. Ceremonies Performed in the Last Pregnancy/Delivery $(n=116)$

\begin{tabular}{cccccc}
\hline Ceremony & Frequency & $\%$ & $\chi^{2}$ & df & p-value \\
\hline Prayers & 82 & 70.7 & 0.275 & 1 & 0.600 \\
Offerings & 32 & 27.6 & 1.884 & 1 & 0.170 \\
Cleansing & 2 & 1.6 & 0.004 & 1 & 0.950 \\
Total & 116 & 100 & & & \\
\hline \multicolumn{5}{c}{ Source: Research } &
\end{tabular}

Source: Research data 2010

\subsection{Analysis and discussion}

Socio-cultural factors are vital in determining people's ability to control their environment. The study data illustrated women as the principal decision maker but with a chain of other influential decision makers within the family and the community. This is of the same view with previous studies such as the 2008-2009 KDHS [11] and a survey conducted in Rural Gambia in 2014 [7]. However, the decision making role to acquire treatment outside of the home is a complex pattern, in many cases, a chain of family members and trusted community members participate in the decision to leave home for care. This may occur in cases where the woman is poor and relies on others for finances or even assistance during transportation. Poverty has various manifestations including lack of income and productive resources sufficient to ensure sustainable livelihood. This is confirmed by a situation analysis conducted in Zimbabwe which listed poverty as one of the reasons for most traditional birth assisted deliveries. The traditional birth attendants are responsive to the socio-cultural and economic needs of women. Payments for the services provided are negotiable and are in terms of crops or even domestic animals [17].

It also emerged that a large proportion of the respondents were not aware of any cultural taboos or beliefs that do not allow women to deliver in a health facility. This is probably because most of the people 
had been converted to Christianity. Christian teachings discourage some cultural practices, which are labeled as morally unacceptable. These findings agree with studies in Bangladesh that found significant association between religion and safe maternity delivery practices [18]. A study conducted in Urban Accra, Ghana found that socio-cultural practices interpreted some occurrences during pregnancy and labour as threats. These heightened the women's anxieties forcing them to seek care from both traditional and conventional providers. A study carried out in Madagascar noted similar health care practices [5],[19].

\section{CONCLUSION}

The results indicate that women's parity, decision making and religion were significant in use of skilled childbirth services. However, cultural taboos, age and marital status did not indicate any relationship. The study recommends effective policies to improve safe maternity delivery practices in Kenya. Appropriate behaviour change strategies by government and Non-governmental Organizations should be undertaken to make the multiparas and older women aware of the benefits of safe maternity delivery. The government should ensure integration of cultural, spiritual, health and healing practices.

\section{ACKNOWLEDGEMENTS}

We appreciate all those who made it possible for us to successfully undertake the study. We wish to convey our gratitude to Dr. Margaret Kaseje and Margaret Nduta of Great Lakes University of Kisumu for their assistance. We further extend our gratitude to all the Public Health officers and the Provincial Administrators of Kaiti Division for their invaluable support during the study. We are grateful to all our peers for their information.

\section{REFERENCES}

[1] Family Care International, "Testing approaches for increasing skilled care during childbirth: Key findings," The skilled care initiative. USA, Family Care International, 2007.

[2] Kebede D., et al., "Assessment of Skilled Birth attendance Among Women of Child bearing Age (15-49) in Yirgacheffe Town, Gedeo Zone, South Ethiopia," International Journal of Science and Research (IJSR), vol/issue: 4(9), 2015.

[3] WHO, "Making pregnancy safer," Geneva, World health organization, 2004c.

[4] R. Moindi, et al., "Why mothers still deliver at home understanding factors associated with home deliveries and cultural practices in rural coastal Kenya, a cross-sectional study," BMC Public Health, vol. 16, pp. 114, 2015.

[5] P. D. Gyeke, et al., "The influence of socio-cultural interpretations of pregnancy threats on health seeking behavior among pregnant women in Urban Accra, Ghana," BMC Pregnancy and child birth, vol. 13, pp. 211, 2013.

[6] UN, "The millennium development goals report 2005," New York, United Nations, 2005.

[7] P. Lerberg, et al., "Barriers to Skilled Birth attendance: A survey among mothers in Rural Gambia," African Journal of Reprodcutive Health, vol/issue: 18(1), pp. 35-43, 2014

[8] WHO, "Proportion of births attended by a skilled attendant-2007 updates, WHO facts sheet," Geneva, World health organization, 2007.

[9] Population action international, "A measure of survival: Calculating women's sexual and reproductive risk," Population action international, 2007.

[10] CBS, "Kenya Demographic and Health survey (KDHS)," Nairobi, Central Bureau of statistics, 2003.

[11] KNBS, "Kenya Demographic and Health survey (KDHS 2008-2009)," Nairobi, Kenya National Bureau of statistics, 2009.

[12] KNBS, "Kenya Demographic and Health survey (KDHS 2014)," Nairobi, Kenya National Bureau of statistics, 2014.

[13] Ministry of Health Makueni, "Health management information system reports (2000-2009)," Ministry of health, Makueni, 2009.

[14] Ministry of Health Makueni, “Annual operations plan 5(2009-2010),” 2009.

[15] Ministry of state for planning national development and vision 2030 Makueni, "Makueni-district development plan 2008-2012; a globally competitive and prosperous nation with a high quality of life by the year 2030," Ministry of Planning Makueni, 2008.

[16] A. Fisher, et al., "Handbook for Family Planning Operations Research Designs (2nd Edition)," New York, Population council, 1998.

[17] N. Choguya, "Traditional and Skilled Birth Attendants in Zimbabwe: A situational Analysis and some policy considerations," Journal of Anthropology, 2015.

[18] M. Rahman, et al., "Determinants of maternity delivery practices in Bangladesh. A logistic analysis," Pakistan journal of social sciences, vol/issue: 5(6), pp. 597-601, 2008.

[19] J. Morris, et al., "Maternal health practices, beliefs and traditions in South East Madagascar," African Journal of Reproductive Health, vol/issue: 18(3), pp. 101-117, 2014. 


\section{BIOGRAPHIES OF AUTHORS}

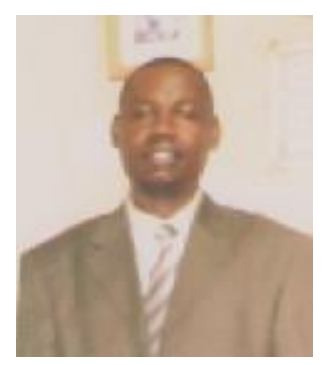

Anthony Wambua Mathulu (Bsc. Public Health, Master in Community Health, PhD (Public Health -ongoing)

Unit Head, Ambulance Services, Department of Health,

Government of Makueni County, Kenya

P.o Box 89,90300 Wote (Kenya)

E-mail:mathulu@yahoo.com;amathulu@gmail.com ;Tel:254 0721672634, 0735622286

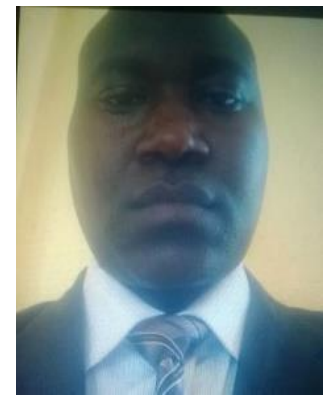

Bernard Wambua Mbithi (Bsc. N, MPH, PhD (Nursing-ongoing)) Lecturer, School of Nursing,

JomoKenyatta University of Agriculture and Technology, Kenya P.o Box62000-00200,

Nairobi.

E- mail: bwmbithi@yahoo.co.uk; Tel:254 0722321945 